\title{
Association of Asthma Diagnosis and Medication Use with Fecundability: A Prospective Cohort Study
}

This article was published in the following Dove Press journal:

Clinical Epidemiology

\author{
Holly Michelle Crowe (D) \\ Lauren Anne Wise (D) \\ Amelia Kent Wesselink' \\ Kenneth Jay Rothman 1,2 \\ Ellen Margrethe Mikkelsen ${ }^{3}$ \\ Henrik Toft Sørensen (D) $^{3}$ \\ Allan Jay Walkey iD $^{4}$ \\ Elizabeth Elliott Hatch' \\ 'Department of Epidemiology, Boston \\ University School of Public Health, \\ Boston, MA 02II8, USA; ${ }^{2}$ RTI \\ International, Raleigh, NC 27709, USA; \\ ${ }^{3}$ Department of Clinical Epidemiology, \\ Aarhus University, Aarhus N 8200, \\ Denmark; ${ }^{4}$ Boston University School of \\ Medicine, Boston, MA 02118, USA
}

Purpose: Asthma has been positively associated with irregular menses and infertility in some studies, but data are limited on the relation between asthma medication use and fecundability (i. e., average per-cycle probability of conception among non-contracepting couples). This study examines the extent to which a history of asthma, asthma medication use, and age at first asthma diagnosis are associated with fecundability among female pregnancy planners.

Participants and Methods: Pregnancy Study Online (PRESTO) is an ongoing, web-based preconception cohort study of couples aged 21-45 years from North America. Between July 2013 and July 2019, a total of 10,436 participants enrolled in PRESTO, and 8286 were included in the present analysis. At study enrollment, women reported whether they had ever been diagnosed with asthma and, if so, the year they were first diagnosed. Women who reported ever being diagnosed with asthma were asked about medication use, including medication type and frequency of use. Participants completed follow-up questionnaires every 8 weeks for up to 12 months or until pregnancy. Proportional probabilities regression models were used to estimate fecundability ratios (FRs) and 95\% confidence intervals (CIs), adjusting for potential confounders. Fecundability ratios below 1.00 indicate reduced probability of conception.

Results: There was little association between a history of asthma diagnosis or asthma medication use and fecundability. Compared with no history of asthma, the FR for ever-diagnosis of asthma with medication use was 1.02 (95\% CI: 0.91-1.15) and for ever-diagnosis of asthma without medication use was 1.00 (95\% CI: 0.91-1.09). Highest intensity asthma medication use (daily plus extra dosing for symptoms), combination inhaled corticosteroid and long-acting betaagonist inhaler use, and a first diagnosis of asthma after age 17 years were associated with small reductions in fecundability.

Conclusion: The present study provides little evidence that asthma or asthma medication use is adversely associated with fecundability.

Keywords: corticosteroid, beta agonist, time to pregnancy, fertility

\section{Introduction}

Asthma is a chronic inflammatory disease of the lungs that is usually managed by a combination of short-acting beta-agonists and inhaled corticosteroids. ${ }^{1}$ According to the Centers for Disease Control and Prevention, the prevalence of asthma among young adults (ages 22-39) is 6.5\%. ${ }^{2}$ Among all adults with currently active asthma, 39\% report use of long-term asthma control medications, and 24\% report frequent use of rescue medications. 3,4

As the prevalence of asthma among women of childbearing years has increased in recent decades, research into associations between asthma and reproductive 
health is of high public health significance. ${ }^{5}$ The preconception period can be a time of increased concern about the unintended effects of medication use, particularly with regards to fertility. Infertility affects $10-15 \%$ of couples and can impose a significant economic and emotional burden on affected couples. Thus, research into modifiable risk factors for infertility is imperative. ${ }^{8,9}$ Treating asthma during the preconception period may be important for perinatal outcomes, as uncontrolled asthma during pregnancy has been associated with adverse perinatal outcomes. ${ }^{6,7}$ Current clinical guidelines state that the risks of uncontrolled asthma generally outweigh the potential harms of using asthma medications for those who are anticipating pregnancy. ${ }^{10}$

Asthma may affect fertility through hormonal alterations or chronic inflammation. ${ }^{11,12}$ Asthma has been associated with abnormal levels of sex steroid hormones and irregular menses in several studies, including a large, multi-center cohort study. ${ }^{12}$ Svanes et al proposed a common inflammatory etiology for asthma and allergy, and endometriosis, which could affect fertility. ${ }^{12}$ Asthma medications with systemic anti-inflammatory effects also may influence the inflammatory process of implantation. ${ }^{13}$ However, the exact mechanism and impact on fertility are not well established. ${ }^{11,12,14}$

The few previous studies examining the association of asthma with fertility have had mixed results. ${ }^{15-18}$ In a registry study of 491,516 women, asthma was not associated with decreased fertility rates, defined as live births per 1000 person-years (fertility rate ratio $=1.02,95 \%$ confidence interval (CI): 1.00-1.04). ${ }^{15}$ In contrast, a prospective cohort study of 245 women undergoing fertility treatment found that women with a diagnosis of asthma were less likely to conceive than women without asthma (hazard ratio $=0.50,95 \%$ CI: $0.34-0.74) .^{16}$

A registry study of twins aged 12-41 found that asthma was associated with infertility (odds ratio $(\mathrm{OR})=1.31$, CI: 1.1-1.6), but that treated patients had a lower risk of infertility $(23.8 \%)$ than untreated patients $(30.5 \%) .{ }^{17}$ This finding was based on small numbers, including 65 treated asthma patients and 60 untreated patients. In contrast, a case-control study found that women who reported using asthma medications before age 21 had greater than double the risk of anovulatory infertility $(\mathrm{OR}=2.5$, CI: $1.0-5.9) .{ }^{18}$ The study also found a threefold increased risk for users of betaagonists, although the estimate was based on only 39 asthma medication users ( 8 cases and 31 controls). Hansen et al ${ }^{19}$ found a relationship between asthma and the need for fertility treatment, particularly among women older than 35 years
$(\mathrm{OR}=2.2$, CI: 1.47-3.07), but no association between asthma severity or use of inhaled corticosteroids and fertility treatment.

Few previous studies have accounted for a variety of medication classes and their combinations or used detailed data to control for potential confounders, including reproductive history, lifestyle factors, and comorbid conditions. No previous studies have looked at fecundability prospectively or examined the association between age at first asthma diagnosis and fecundability. To fill these gaps in the literature, we used self-reported data from a preconception cohort of North American pregnancy planners to examine the association between a history of asthma, age at first asthma diagnosis, asthma medication use (including medication type and frequency), and fecundability, defined as the average per-cycle probability of conception among non-contracepting couples.

\section{Participants and Methods}

Pregnancy Study Online (PRESTO) is an ongoing, web-based preconception cohort study that aims to identify how behavioral, dietary, medical, and other factors impact fertility. The study methods have been described in detail elsewhere. ${ }^{20}$ Briefly, women are eligible for participation if they are aged 21-45 years, residing in the US or Canada, in a stable relationship with a male partner, and not using contraception or fertility treatment. Participants complete an online baseline questionnaire with items on demographics, lifestyle, medical and reproductive histories, and medication use, and follow-up questionnaires every 8 weeks for up to 12 months to ascertain pregnancy status. Participants received nominal lottery-based incentives for participation. This study was approved by the Institutional Review Board at Boston University Medical Campus, and online informed consent was obtained from all participants.

From July 2013 through July 2019, 10,436 eligible women completed the baseline questionnaire. We excluded 118 women whose date of last menstrual period (LMP) at baseline was more than 6 months in the past, and 30 women with missing/implausible LMP data. We then excluded 2084 women who had been trying to conceive for more than 6 cycles at baseline, to reduce the potential for reverse causation (eg, subfertility causing changes in medication use). We included 8286 women in the analysis.

\section{Assessment of Exposure}

At baseline, women reported whether they had ever been diagnosed with asthma and, if so, the year when they were first diagnosed. We calculated age at first diagnosis by 
subtracting year of birth from year at first diagnosis. Women who indicated ever receiving an asthma diagnosis were asked to report whether they had taken asthma medication in the last 4 weeks at baseline. If they reported using asthma medication, they were asked if they took medication "daily," "when having symptoms," or "daily plus extra due to symptoms." Women provided the names of their asthma medication in up to two open text boxes. On each follow-up questionnaire, women provided updated information on asthma medication use in the last 4 weeks, medication use frequency, and medication name.

\section{Assessment of Outcome}

The outcome of interest was fecundability. The underlying variable used to calculate fecundability is time to pregnancy. At baseline, participants reported their last menstrual period (LMP) date, usual cycle length, and the number of cycles they had attempted conception. On online follow-up questionnaires administered every 2 months, participants reported their most recent LMP date and whether they had become pregnant since the previous questionnaire. Total discrete cycles at risk were calculated as follows: cycles of attempt at study entry + [(LMP from most recent follow-up questionnaire - date of baseline questionnaire completion)/usual cycle length] +1 . Participants contributed observed cycles to the analysis from baseline until reported conception, loss to follow-up, withdrawal, initiation of fertility treatment, no longer trying to conceive, or 12 cycles, whichever came first. Pregnancies were identified through follow-up questionnaires. Additional pregnancy data was obtained via linkages with birth registries in select states and through online searches (e.g., baby registries, birth announcements).

\section{Assessment of Covariates}

We selected potential confounders a priori based on available literature and a causal diagram. Information collected on baseline questionnaires included age, body mass index (BMI), race/ethnicity, education, household income, smoking status, last method of birth control, intercourse frequency, doing something to improve chances of getting pregnant (e.g., charting menstrual cycles, taking basal body temperature), physical activity, region of residence, source used to pay for healthcare, number of primary care physician visits in the past year, depressive symptoms, perceived stress, and history of anxiety, depression, or hay fever. Total metabolic equivalents of task (METs) of physical activity were calculated by multiplying the average number of hours per week engaged in various activities by metabolic equivalents estimated from the Compendium of Physical Activities. ${ }^{21}$

\section{Data Analysis}

Asthma medications reported as free text were classified according to their active ingredients into four medication classes (Supplemental Table 1): inhaled corticosteroids, combination inhaled corticosteroids and long-acting betaagonists, leukotriene inhibitors, and short-acting betaagonists. Medication classes were not mutually exclusive. Asthma medication use in the last 4 weeks was examined at baseline only and as a time-varying exposure.

Pharmacologic asthma treatment involves a stepwise approach, with patients starting by taking a short-acting beta-agonist as needed, and then increasing medication to control more severe or persistent symptoms. ${ }^{22}$ In order to address confounding by asthma severity, we examined fecundability in groupings of asthma treatment escalation. We considered group 1 (short-acting beta-agonist only) as indicating mild asthma, group 2 (maintenance medication only) as indicating persistent asthma, and groups 3 (shortacting beta-agonist and inhaled corticosteroid) and 4 (additional medication combinations) as indicating more severe asthma. Maintenance medications included inhaled corticosteroids, combination inhaled corticosteroid and longacting beta-agonists, and leukotriene modifiers. Treatment groups were mutually exclusive.

We used life-table methods to compute the proportion of participants who conceived over follow-up, accounting for censoring. ${ }^{23}$ We used proportional probabilities regression to estimate fecundability ratios (FR), the per-cycle probability of conception comparing exposed with unexposed individuals, and 95\% confidence intervals (CI), adjusting for potential confounders. Fecundability ratios below 1.00 indicate reduced probability of conception. ${ }^{24}$

Results were adjusted for age $(<25,25-29,30-34, \geq 35$ years), BMI $\left(<18,18-24,25-29,30-34, \geq 35 \mathrm{~kg} / \mathrm{m}^{2}\right)$, race (non-Hispanic white, non-Hispanic black, Hispanic, Asian, other), education ( $\leq 12,13-15,16, \geq 17$ years), household income $(<\$ 50,00, \$ 50,00-149,000, \geq \$ 150,000)$, source used to pay for healthcare(private insurance purchased directly, private insurance through employer, government insurance, free clinic, out of pocket), number of primary care physician visits in the past year (continuous), smoking status (never, former, current occasional, current regular), last method of birth control (hormonal, non-hormonal), intercourse frequency ( $<1,1-3, \geq 4$ times per week), doing something to improve chances of getting pregnant (yes, no), 
moderate and vigorous MET-hours (continuous), region of residence (Northeast, South, Midwest, West, Canada), depressive symptoms (Major Depression Inventory score $^{25}$ ), stress (Perceived Stress Scale score-10 ${ }^{26}$ ), anxiety diagnosis, depression diagnosis, and hay fever diagnosis. Stratified analyses were conducted according to the number of cycles of attempted pregnancy at study entry ( $<3$ vs 3-6 cycles) to address potential reverse causation by behavioral change in response to increasing time to pregnancy. Stratified analyses were also conducted according to age ( $<35$ vs $\geq 35$ years) and BMI ( $<25 \mathrm{vs} \geq 25 \mathrm{~kg} / \mathrm{m}^{2}$ ), as previous literature suggests that increasing age and BMI may exacerbate the effects of asthma on fertility. ${ }^{16,19}$

We used multiple imputation to generate values for missing baseline and follow-up data on exposure, covariates, and pregnancy status. As the asthma medication name question was added in May 2016, the percent missing was $34 \%$. For women missing asthma medication name, each medication class was imputed as a binary response. The information was assumed missing at random contingent on whether the participant filled out the questionnaire before or after the question was added. The distributions of medication classes before and after imputation were similar (within $2 \%$ for each medication class). Missingness for covariates ranged from $<1 \%$ (eg, last method of birth control) to $3 \%$ (income). We assigned one cycle of observation to the $15 \%$ of participants who did not complete any follow-up questionnaires and imputed the outcome of that cycle (pregnant vs not). We created five imputed datasets and statistically combined coefficient and standard error estimates from the five data sets.

\section{Results}

\section{Cohort Characteristics}

The analytic cohort included 8286 women with 4461 observed pregnancies over 31,113 menstrual cycles. During follow-up, $54 \%$ of women became pregnant $(72 \%$ after accounting for censoring using life-tables methods), $14 \%$ did not become pregnant within 12 cycles, $3 \%$ stopped trying to conceive, $7 \%$ began fertility treatment, $2 \%$ were still actively participating, and $20 \%$ were lost to follow-up. Loss to follow-up did not materially differ by asthma status (21\% of women with asthma and $19 \%$ of those without asthma). The average age of women in this study was 30 years old. The majority of participants lived in the US (84\%), and the remaining 16\% were residents of Canada. Additional cohort characteristics are presented in Table 1.
Seventeen percent of women $(n=1381)$ reported ever being diagnosed with asthma. Among women with a history or asthma, 14\% were first diagnosed at age $<5$ years, 59\% were first diagnosed from ages 5-17 years, and 27\% were first diagnosed at age $\geq 18$ years. Among women with an everdiagnosis of asthma, 469 (34\%) women reported taking 688 asthma medications in the past 4 weeks. Of these women, $59 \%$ took medication only when symptomatic, $20 \%$ took medication daily, and $21 \%$ took medication daily with additional dosing as needed for symptoms. Sixty-three percent of reported medications were short-acting beta-agonists, 16\% were combination corticosteroid and long-acting betaagonists, $11 \%$ were inhaled corticosteroids and $10 \%$ were leukotriene inhibitors. When we categorized medication use by treatment escalation, $59 \%$ used only a short-acting betaagonist (group 1), 10\% used only a maintenance medication (group 2), 14\% used an inhaled corticosteroid (without longacting beta-agonist) and short-acting beta-agonist (group 3), and $17 \%$ used any other combination of maintenance medications and short-acting beta-agonist (group 4).

Indicators of poor health were not unilaterally more frequently observed among those with an asthma diagnosis or medication use (Table 1). Women with an asthma diagnosis or asthma medication use had slightly higher mean BMI than women without asthma, but BMI was similar across medication use frequency categories. Physical activity was higher among women with asthma, regardless of asthma medication use. Current regular smoking was more frequently observed among those taking asthma medication, particularly those taking medication daily or daily and more when symptomatic. Women with an asthma diagnosis who did not take medication were less often smokers than those without asthma. Having been diagnosed with asthma was observed to coincide with diagnoses of anxiety, depression, and hay fever.

\section{History of Asthma and Asthma Medication Use}

We found little association between an ever-diagnosis of asthma, with or without medication use, and fecundability (Table 2). Compared with women without a history of asthma, the FR for women with an ever-diagnosis of asthma who also used medication was 1.02 (CI: 0.91-1.15), and the FR for women with an ever-diagnosis of asthma who did not use medication was 1.00 (CI: 0.91-1.09). Frequency of medication use was not generally associated with fecundability, with the exception of daily asthma medication use with 
Table I Baseline Characteristics ${ }^{\mathrm{a}}$ of 8286 Female Pregnancy Planners by Asthma Diagnosis and Medication Use

\begin{tabular}{|c|c|c|c|c|c|c|}
\hline \multirow[t]{3}{*}{ Characteristic } & \multicolumn{6}{|c|}{ Asthma Medication Use } \\
\hline & \multicolumn{4}{|c|}{ Asthma Diagnosis and Medication Use in Last 4 Weeks } & \multirow{2}{*}{$\begin{array}{l}\text { Asthma Diagnosis } \\
\text { and no Medication } \\
\text { Use in Last } 4 \\
\text { Weeks }\end{array}$} & \multirow{2}{*}{$\begin{array}{l}\text { No Asthma } \\
\text { Diagnosis }\end{array}$} \\
\hline & $\begin{array}{l}\text { When Having } \\
\text { Symptoms }\end{array}$ & Daily & $\begin{array}{l}\text { Daily \& When } \\
\text { Having Symptoms }\end{array}$ & Overall & & \\
\hline n (\%) & 272 & 95 & 97 & $469(5.7)$ & $912(11.0)$ & $6905(83.3)$ \\
\hline $\begin{array}{l}\text { Proportion of those with asthma } \\
\text { diagnosis }^{b}\end{array}$ & 19.7 & 6.9 & 7.0 & 34.0 & 66.0 & $\mathrm{~N} / \mathrm{A}$ \\
\hline Age at baseline (years), mean & 29.5 & 30.4 & 30.1 & 29.8 & 29.5 & 29.9 \\
\hline Age at asthma diagnosis, mean & 14.1 & 14.9 & 14.6 & 14.5 & 12.7 & $\mathrm{~N} / \mathrm{A}$ \\
\hline \multicolumn{7}{|l|}{ Education, \% } \\
\hline Less than college & 6.4 & 7.4 & 7.5 & 7.0 & 4.9 & 5.2 \\
\hline Some college & 31.6 & 25.7 & 24.8 & 28.9 & 22.7 & 22.3 \\
\hline College graduate & 28.2 & 25.3 & 37.3 & 28.9 & 34.5 & 34.6 \\
\hline Graduate school & 33.8 & 41.5 & 30.4 & 35.1 & 37.8 & 37.9 \\
\hline \multicolumn{7}{|c|}{ Household income (US dollars/year), \% } \\
\hline$<50,000$ & 29.0 & 27.7 & 25.5 & 28.4 & 21.4 & 19.9 \\
\hline $50,000-99,999$ & 37.4 & 35.6 & 43.2 & 37.6 & 37.4 & 38.8 \\
\hline $100,000-149,000$ & 23.1 & 28.3 & 17.2 & 23.2 & 24.4 & 25.9 \\
\hline$\geq 150,000$ & 10.5 & 8.4 & 14.1 & 10.8 & 16.7 & 15.4 \\
\hline \multicolumn{7}{|l|}{$\begin{array}{l}\text { Primary care provider visits, } \\
\text { past year, } \%\end{array}$} \\
\hline 0 & 8.7 & 3.3 & 2.1 & 6.1 & 10.5 & 12.1 \\
\hline 1 & 20.3 & 18.8 & 17.5 & 19.1 & 27.8 & 31.9 \\
\hline $2-3$ & 46.0 & 47.4 & 46.0 & 46.3 & 42.4 & 40.5 \\
\hline $4-5$ & 15.1 & 20.3 & 17.5 & 17.0 & 11.9 & 9.3 \\
\hline$\geq 6$ & 10.0 & 10.3 & 16.9 & 11.5 & 7.4 & 6.0 \\
\hline \multicolumn{7}{|l|}{ Race/ethnicity, \% } \\
\hline White, non-Hispanic & 83.1 & 86.0 & 87.6 & 84.7 & 83.9 & 84.1 \\
\hline \multicolumn{7}{|l|}{ Region of residence, \% } \\
\hline Northeast & 23.9 & 24.3 & 17.3 & 22.7 & 24.2 & 22.2 \\
\hline South & 22.3 & 29.6 & 12.2 & 21.7 & 22.7 & 24,6 \\
\hline Midwest & 18.8 & 21.2 & 31.1 & 22.0 & 19.5 & 21.0 \\
\hline West & 15.5 & 13.2 & 16.5 & 15.1 & 17.3 & 15.9 \\
\hline Canada & 19.5 & 11.7 & 22.9 & 18.5 & 16.4 & 16.3 \\
\hline Urban, \% & 69.5 & 76.4 & 59.4 & 69.1 & 69.2 & 69.9 \\
\hline BMI $\left(\mathrm{kg} / \mathrm{m}^{2}\right)$, mean & 29.9 & 29.4 & 30.5 & 29.9 & 28.8 & 27.7 \\
\hline \multicolumn{7}{|l|}{ Physical activity (MET-hrs) } \\
\hline Moderate Physical Activity, mean & 19.9 & 16.6 & 20.2 & 19.1 & 17.9 & 16.8 \\
\hline Vigorous Physical Activity, mean & 17.7 & 20.1 & 17.8 & 18.2 & 17.0 & 16.7 \\
\hline \multicolumn{7}{|l|}{ Smoking, \% } \\
\hline Never Smoker & 69.1 & 74.4 & 66.9 & 69.5 & 76.1 & 74.8 \\
\hline Former Smoker & 16.8 & 14.8 & 13.0 & 15.5 & 14.6 & 14.5 \\
\hline Current Occasional Smoker & 3.4 & 3.6 & 8.4 & 4.5 & 4.1 & 3.8 \\
\hline Current Regular Smoker & 10.7 & 7.3 & 11.7 & 10.6 & 5.2 & 7.0 \\
\hline Married, \% & 86.8 & 92.0 & 82.9 & 87.3 & 89.6 & 90.3 \\
\hline Nulliparous, \% & 71.0 & 70.0 & 71.3 & 70.6 & 64.8 & 66.8 \\
\hline
\end{tabular}

(Continued) 
Table I (Continued).

\begin{tabular}{|c|c|c|c|c|c|c|}
\hline \multirow[t]{3}{*}{ Characteristic } & \multicolumn{6}{|c|}{ Asthma Medication Use } \\
\hline & \multicolumn{4}{|c|}{ Asthma Diagnosis and Medication Use in Last 4 Weeks } & \multirow{2}{*}{$\begin{array}{l}\text { Asthma Diagnosis } \\
\text { and no Medication } \\
\text { Use in Last } 4 \\
\text { Weeks }\end{array}$} & \multirow{2}{*}{$\begin{array}{l}\text { No Asthma } \\
\text { Diagnosis }\end{array}$} \\
\hline & $\begin{array}{l}\text { When Having } \\
\text { Symptoms }\end{array}$ & Daily & $\begin{array}{l}\text { Daily \& When } \\
\text { Having Symptoms }\end{array}$ & Overall & & \\
\hline $\begin{array}{l}\text { Last method of contraception was } \\
\text { hormonal \% }\end{array}$ & 43.0 & 43.1 & 36.7 & 41.6 & 35.0 & 38.6 \\
\hline \multicolumn{7}{|l|}{ Intercourse frequency (times/week), \% } \\
\hline$<1$ & 23.7 & 17.4 & 26.7 & 22.9 & 21.6 & 20.7 \\
\hline$\geq 4$ & 19.2 & 14.1 & 18.9 & 18.2 & 15.2 & 16.3 \\
\hline $\begin{array}{l}\text { Doing something to improve chances } \\
\text { of conception }\end{array}$ & 80.9 & 79.0 & 74.2 & 79.3 & 74.5 & 76.5 \\
\hline \multicolumn{7}{|l|}{ Mental health diagnosis, \% } \\
\hline Anxiety & 33.0 & 43.8 & 35.3 & 36.0 & 30.9 & 22.5 \\
\hline Depression & 33.7 & 34.5 & 31.8 & 33.1 & 31.8 & 23.9 \\
\hline Hay Fever Diagnosis, \% & 23.2 & 31.7 & 30.4 & 26.0 & 16.7 & 6.7 \\
\hline
\end{tabular}

Notes: ${ }^{a}$ All characteristics except for age are standardized to baseline age of cohort. ${ }^{\mathrm{b}}$ These percentages refer to the distribution of medication use among participants who reported being ever diagnosed with asthma. For example, 19.7\% of participants who report being ever diagnosed with asthma took medication when having symptoms.

additional dosing for symptoms, which was associated with slightly reduced fecundability (FR 0.89, CI: 0.68-1.16). Our findings did not materially differ across strata of age, BMI (data not shown) or cycles of attempted pregnancy at study entry (Supplemental Table 2).

Asthma medication use and frequency of use were analyzed at baseline and as time-varying exposures to account for medication initiation or discontinuation during follow-up. During follow-up, 17 (4\%) women initiated and 103 (22\%) women discontinued asthma medication for at least one follow-up interval. Almost all of the medications initiated or discontinued were short-acting beta-agonists, which can be used as needed in less severe cases of asthma. Baseline and time-varying results were similar (data not shown).

\section{Medication Class}

We found little association between the use of corticosteroidonly inhalers, leukotriene inhibitors, or short-acting betaagonists and fecundability, compared with those never diagnosed with asthma (Table 2). We found slightly lower fecundability among women using combination corticosteroids and long-acting beta-agonists compared with those without a history of asthma (FR 0.86, CI: 0.66-1.12), although the numbers of pregnancies in each medication class were small. Treatment in group 3 of the asthma treatment escalation was associated with slightly improved fecundability (FR 1.29, CI: 0.85-1.97), and treatment in group 4 was associated with slightly reduced fecundability (FR 0.85, CI: 0.62-1.18), although these estimates were imprecise.

\section{Age at First Asthma Diagnosis}

We found little association between being first diagnosed with asthma at $<5$ years or 5-17 years and fecundability, compared with women who had never been diagnosed with asthma (FR 1.04, CI: 0.85-1.26 and FR 1.01, CI: 0.92-1.12, respectively). We found slightly reduced fecundability among women who were first diagnosed with asthma as adults (age $\geq 18$ years vs never diagnosis: FR 0.89, CI: 0.77-1.04).

\section{History of Asthma and Asthma Medication Use and Infertility}

As an additional analysis, we used multivariable log binomial models to analyze the association between a history of asthma and asthma medication use and infertility. Participants who did not become pregnant within 12 months of attempting to conceive were considered infertile. In this analysis, the risk ratio for a history of asthma, as compared to no history of asthma, and infertility was 1.02 (95\% CI: 0 .88-1.18), controlling for age, BMI, race, income, and education. The risk ratio for a history of asthma and medication 
Table 2 Asthma Medication Use and Fecundability Among 8286 Female Pregnancy Planners

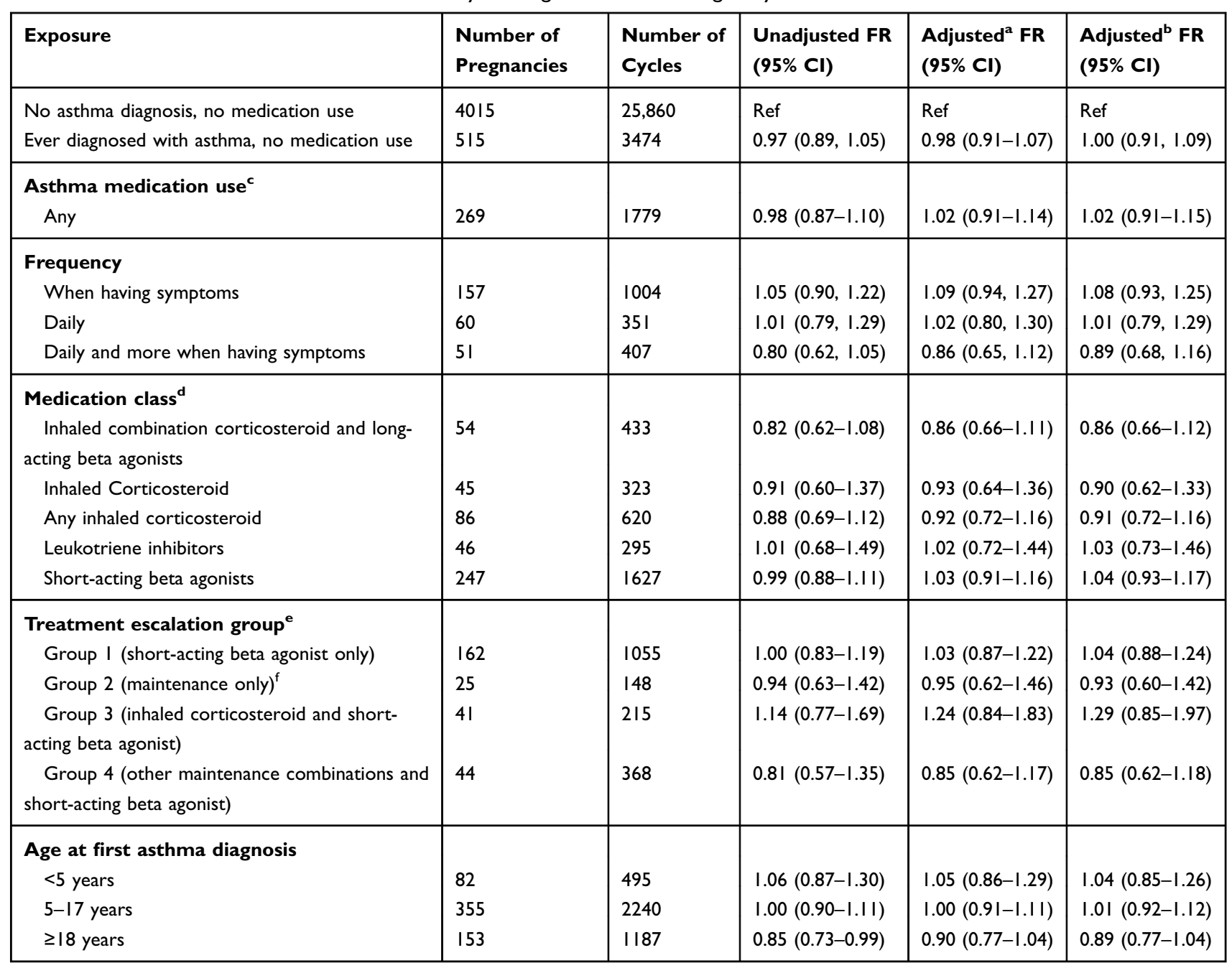

Notes: age, BMI, race, education, income bage, BMI, race, education, income, smoking status, hormonal birth control as last form of birth control, intercourse frequency, doing something to improve chances of getting pregnant, physical activity, region of residence, anxiety diagnosis, depression diagnosis, hay fever diagnosis, health insurance, primary care provider visits, MDI score, PSS score ${ }^{c}$ self-reported use in the last four weeks, at baseline ${ }^{d}$ not mutually exclusive ${ }^{e}$ mutually exclusive ${ }^{f}$ maintenance medications include inhaled corticosteroids, inhaled combination corticosteroid and long-acting beta-agonists, and leukotriene inhibitors.

use, as compared to a history of asthma and no medication use, and infertility was 1.15 (95\% CI: 0.87-1.51), controlling for age, BMI, race, income, and education.

\section{Discussion}

Overall, we found little association between a history of asthma and medication use and fecundability. We found slight reductions in fecundability among women using combination corticosteroid/long-acting beta-agonist inhalers, women who used medication daily and more when symptomatic, and women who were diagnosed with asthma in adulthood $(\geq 18$ years). When we used asthma treatment escalation groups as a proxy for asthma severity, there was no indication of a doseresponse relationship between presumed asthma severity and fecundability, although estimates were imprecise. We found little association between a history of asthma and infertility, as compared to no history of asthma, and a slightly increased risk of infertility among those with a history of asthma and medication use, as compared to those with a history of asthma and no medication use.

Relying on self-reported data to ascertain asthma status may have resulted in misclassification of exposure, as women may have had undiagnosed asthma or childhood asthma that has resolved. When comparing self-reported asthma in questionnaires with a clinical diagnosis of asthma, Toren et al reported a sensitivity of $68 \%$ and a specificity of $94 \%$, implying that there are likely some false positives and a considerable proportion of false negatives in our asthma classification. $^{27}$ We lacked data on asthma symptoms or medication use history earlier than the preceding 4 weeks, 
so women with asthma diagnoses who did not use medications likely constituted a heterogeneous group of women with untreated asthma, asthma that did not require treatment, and asthma that no longer required treatment.

While previous studies have shown an association between asthma and infertility, our study shows only slightly reduced fecundability among certain subgroups of women with asthma. Our study design and population may also explain some of this variation. For example, the Screening of Pregnancy Endpoints (SCOPE) study population included only women who became pregnant and relied on selfreported time to pregnancy, making the study vulnerable to selection bias and outcome misclassification. ${ }^{28}$ Grodstein et al's case-control study ascertained asthma retrospectively and included a small number of asthma medication users. ${ }^{18}$

The present study also differs from previous literature in the categorization of asthma medications analyzed. The twin study found that treated asthma was associated with a lower risk of infertility than untreated asthma, ${ }^{17}$ however, investigators did not distinguish between asthma treatments beyond corticosteroids. The SCOPE study found little association between use of inhaled corticosteroids and fecundability when considering corticosteroids with or without long-acting beta-agonists in a single category. ${ }^{28}$ In contrast, our study found a slight reduction in fecundability specifically among women taking corticosteroids with long-acting beta-agonists. Many individuals take multiple types of medications to control their asthma. We were unable to examine all possible combinations of medications, thus differing medication groupings may explain some of the variation in the results of this and previous studies.

This is the first study to analyze the association between age at first asthma diagnosis and fecundability. Adult-onset asthma has a lower remission rate, poorer prognosis, and tends to be more severe than childhood asthma. $^{29}$ The observed effect of age at first asthma diagnosis on fecundability may be due to poorer underlying health, greater asthma severity, or poorer asthma control among women with adult-onset asthma.

Strengths of our study include prospective design, a large cohort, adjustment for many potential confounders, and analysis of treatment by medication class. A concern is residual confounding, particularly by asthma severity or control (i.e., confounding by indication). While the treatment escalation analysis attempted to use treatment regimen as a proxy for asthma severity, the number of pregnancies in each group was too small to draw definitive conclusions. Additional data on asthma severity markers, such as medication dose and lung function, were not available. Missing data were also a concern, as we did not have information on the specific medication used for $34 \%$ of participants who reported using asthma medication. We used multiple imputation to reduce bias from missing data for these participants.

In summary, we found little association between a history of asthma or asthma medication use and fecundability. However, use of asthma medication daily plus more when symptomatic, use of combination corticosteroid/long-acting beta-agonist inhalers, and a first diagnosis of asthma in adulthood were associated with slight reductions in fecundability. Our results support clinical guidelines for the use of asthma medication for women anticipating pregnancy ${ }^{10}$ in that we found little evidence that asthma itself or use of asthma medications are adversely associated with fecundability.

\section{Abbreviations}

BMI, body mass index; CI, confidence interval; FR, fecundability ratio; LMP, last menstrual period; MDI, major depression inventory; MET, metabolic equivalent of task; OR, odds ratio; PRESTO, Pregnancy Study Online.

\section{Acknowledgment}

This study was supported through funds provided by the National Institute of Child Health and Human Development, National Institute of Health (R01-HD086742, R21-HD 072326).

\section{Disclosure}

LAW is a fibroid consultant for AbbVie Inc. HTS reports that the Department of Clinical Epidemiology, Aarhus University Hospital, receives funding for other studies from companies in the form of research grants to (and administered by) Aarhus University. None of these studies have any relation to the present study. The authors have no other conflicts of interest in this work.

\section{References}

1. McCracken JL, Veeranki SP, Ameredes BT, Calhoun WJ. Diagnosis and management of asthma in adults. JAMA. 2017;318(3):279. doi:10.1001/jama.2017.8372

2. Centers for Disease Control and Prevention. Most recent national asthma data | CDC; 2019. Available from: https://www.cdc.gov/asthma/most_ recent_national_asthma_data.htm. Accessed September 17, 2019.

3. Centers for Disease Control and Prevention. Use of long-term control medication among persons with active asthma | CDC; 2014. Available from: https://www.cdc.gov/asthma/asthma_stats/longterm_medication. htm. Accessed September 17, 2019. 
4. Centers for Disease Control and Prevention. AsthmaStats - Frequent use of quick-relief medication among persons with active asthma CDC; 2014. Available from: https:/www.cdc.gov/asthma/asthma stats/overuse.htm. Accessed September 17, 2019.

5. Flores KF, Bandoli G, Chambers CD, Schatz M, Palmsten K. Asthma prevalence among women aged 18 to 44 in the United States: national health and nutrition examination survey 2001-2016. J Asthma. 2019;1-10. doi:10.1080/02770903.2019.1602874

6. Alexander S, Dodds L, Armson BA. Perinatal outcomes in women with asthma during pregnancy. Obstet Gynecol. 1998;92(3):435-440. doi:10.1016/S0029-7844(98)00191-4

7. Bakhireva LN, Schatz M, Jones KL, Chambers CD. Asthma control during pregnancy and the risk of preterm delivery or impaired fetal growth. Ann Allergy Asthma Immunol. 2008;101(2):137-143 doi:10.1016/S1081-1206(10)60201-3

8. Thoma ME, McLain AC, Louis JF, et al. Prevalence of infertility in the United States as estimated by the current duration approach and a traditional constructed approach. Fertil Steril. 2013;99(5):1324 1331.e1. doi:10.1016/j.fertnstert.2012.11.037

9. Chandra A, Copen CE, Stephen EH. Infertility and impaired fecundity in the United States, 1982-2010: data from the National Survey of Family Growth. Natl Health Stat Report. 2013;(67):1-19.

10. Schatz M, Weinberger S. Management of Asthma During Pregnancy. Waltham, MA: Up to Date; 2019. Available from: www.uptodate. com. Accessed May 12, 2020.

11. Boulet L-P, Boulay M-È. Asthma-related comorbidities. Expert Rev Respir Med. 2011;5(3):377-393. doi:10.1586/ers.11.34

12. Svanes C, Real FG, Gislason T, et al. Association of asthma and hay fever with irregular menstruation. Thorax. 2005;60(6):445-450. doi:10.1136/thx.2004.032615

13. Ng SC, Gilman-Sachs A, Thaker P, Beaman KD, Beer AE, KwakKim J. Expression of intracellular Th1 and Th2 Cytokines in women with recurrent spontaneous abortion, implantation failures after IVF/ ET or normal pregnancy. Am J Reprod Immunol. 2002;48(2):77-86. doi:10.1034/j.1600-0897.2002.01105.x

14. Rubio Ravelo L, Gago Rodríguez B, Almirall Collazo JJ, Bell Heredia L, Fernández Fernández L. Comparative study of progesterone, estradiol and cortisol concentrations in asthmatic and non-asthmatic women. Allergol Immunopathol (Madr). 1988;16(4):263-266.

15. Tata L, Hubbard R, McKeever T, et al. Fertility rates in women with asthma, eczema, and hay fever: a general population-based cohort study. Am J Epidemiol. 2007;165(9):1023-1030. doi:10.1093/aje/kwk092

16. Gade EJ, Thomsen SF, Lindenberg S, Backer V. Fertility outcomes in asthma: a clinical study of 245 women with unexplained infertility. Eur Respir J. 2016;47(4):1144-1151. doi:10.1183/13993003.01389-2015
17. Gade EJ, Thomsen SF, Lindenberg S, Kyvik KO, Lieberoth S, Backer V. Asthma affects time to pregnancy and fertility: a register-based twin study. Eur Respir J. 2014;43(4):1077-1085. doi:10.1183/09031936.00148713

18. Grodstein F, Goldman MB, Ryan L, Cramer DW. Self-reported use of pharmaceuticals and primary ovulatory infertility. Epidemiology. 1993;4(2):151-156. doi:10.1097/00001648-199303000-00011

19. Hansen AV, Ali Z, Malchau SS, Blafoss J, Pinborg A, Ulrik CS. Fertility treatment among women with asthma: a case-control study of 3689 women with live births. Eur Respir J. 2019;53(2):1800597. doi:10.1183/13993003.00597-2018

20. Wise LA, Rothman KJ, Mikkelsen EM, et al. Design and conduct of an internet-based preconception cohort study in North America: pregnancy study online. Paediatr Perinat Epidemiol. 2015;29 (4):360-371. doi:10.1111/ppe.12201

21. Ainsworth BE, Haskell WL, Whitt MC, et al. Compendium of physical activities: an update of activity codes and MET intensities. Med Sci Sport Exerc. 2000;32(Supplement):S498-S516. doi:10.1097/ 00005768-200009001-00009

22. Fanta C. An Overview of Asthma Management. Waltham, MA: Up to Date; 2019.

23. Cox DR. Regression models and life-tables. J $R$ Stat Soc Ser B. 1972;34(2):187-202. doi:10.1111/j.2517-6161.1972.tb00899.x

24. Weinberg CR, Wilcox AJ, Baird DD. Reduced fecundability in women with prenatal exposure to cigarette smoking. Am $J$ Epidemiol. 1989;129(5):1072-1078. doi:10.1093/oxfordjournals. aje.a115211

25. Bech P, Rasmussen NA, Olsen LR, Noerholm V, Abildgaard W. The sensitivity and specificity of the Major Depression Inventory, using the Present State Examination as the index of diagnostic validity. $J$ Affect Disord. 2001;66(2-3):159-164. doi:10.1016/s0165-0327(00) 00309-8

26. Cohen S, Kamarck T, Mermelstein R. A global measure of perceived stress. J Health Soc Behav. 1983;24(4):385-396. doi:10.2307/ 2136404

27. Torèn K, Brisman J, Järvholm B. Asthma and asthma-like symptoms in adults assessed by questionnaires. Chest. 1993;104(2):600-608. doi:10.1378/chest.104.2.600

28. Grzeskowiak LE, Smithers LG, Grieger JA, et al. Asthma treatment impacts time to pregnancy: evidence from the international SCOPE study. Eur Respir J. 2018;51(2):1702035. doi:10.1183/13993003. 02035-2017

29. de Nijs SB, Venekamp LN, Bel EH. Adult-onset asthma: is it really different? Eur Respir Rev. 2013;22(127):44-52. doi:10.1183/0905 9180.00007112
Clinical Epidemiology

\section{Publish your work in this journal}

Clinical Epidemiology is an international, peer-reviewed, open access, online journal focusing on disease and drug epidemiology, identification of risk factors and screening procedures to develop optimal preventative initiatives and programs. Specific topics include: diagnosis, prognosis, treatment, screening, prevention, risk factor modification,

Submit your manuscript here: https://wwww.dovepress.com/clinical-epidemiology-journal systematic reviews, risk \& safety of medical interventions, epidemiology \& biostatistical methods, and evaluation of guidelines, translational medicine, health policies \& economic evaluations. The manuscript management system is completely online and includes a very quick and fair peer-review system, which is all easy to use. 